\title{
Correction to: Curcumin-functionalized nanocomposite AgNPs/SDS/MWCNTs for electrocatalytic simultaneous determination of dopamine, uric acid, and guanine in co-existence of ascorbic acid by glassy carbon electrode
}

\author{
Negar Haghnegahdar ${ }^{1}$, Maryam Abbasi Tarighat ${ }^{1, \star}$ (i), and Davoud Dastan ${ }^{2}$ \\ ${ }^{1}$ Department of Chemistry, Faculty of Sciences, Persian Gulf University, 75169 Bushehr, Iran \\ ${ }^{2}$ School of Materials Science and Engineering, Georgia Institute of Technology, Atlanta, GA 30332, USA
}

Published online:

20 February 2021

(C) Springer Science+Business Media, LLC, part of Springer

Nature 2021

\section{Correction to:}

Journal of Materials Science: Materials in Electronics

https:/doi.org/10.1007/s10854-021-05282-1

In the original version of this article unfortunately the first author's family name change has been missed to update. Instead of Motahhareh Haghnegahdar, it should be Negar Haghnegahdar. This has been corrected by publishing this correction article.

The original article has been updated.

Publisher's Note Springer Nature remains neutral with regard to jurisdictional claims in published maps and institutional affiliations.

The original article can be found online at https:// doi.org/10.1007/s10854-021-05282-1.

Address correspondence to E-mail: matarighat@pgu.ac.ir; matarighat@gmail.com 